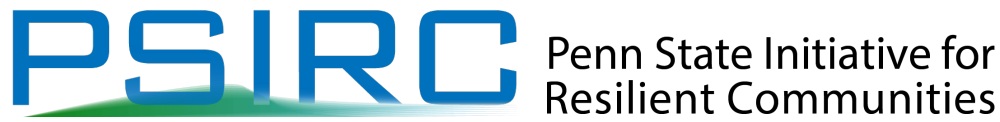

\title{
Establishing Priorities for Pennsylvania Community Flood Resilience White Paper
}

Outcomes from 27 September 2019 Workshop, Selinsgrove, PA
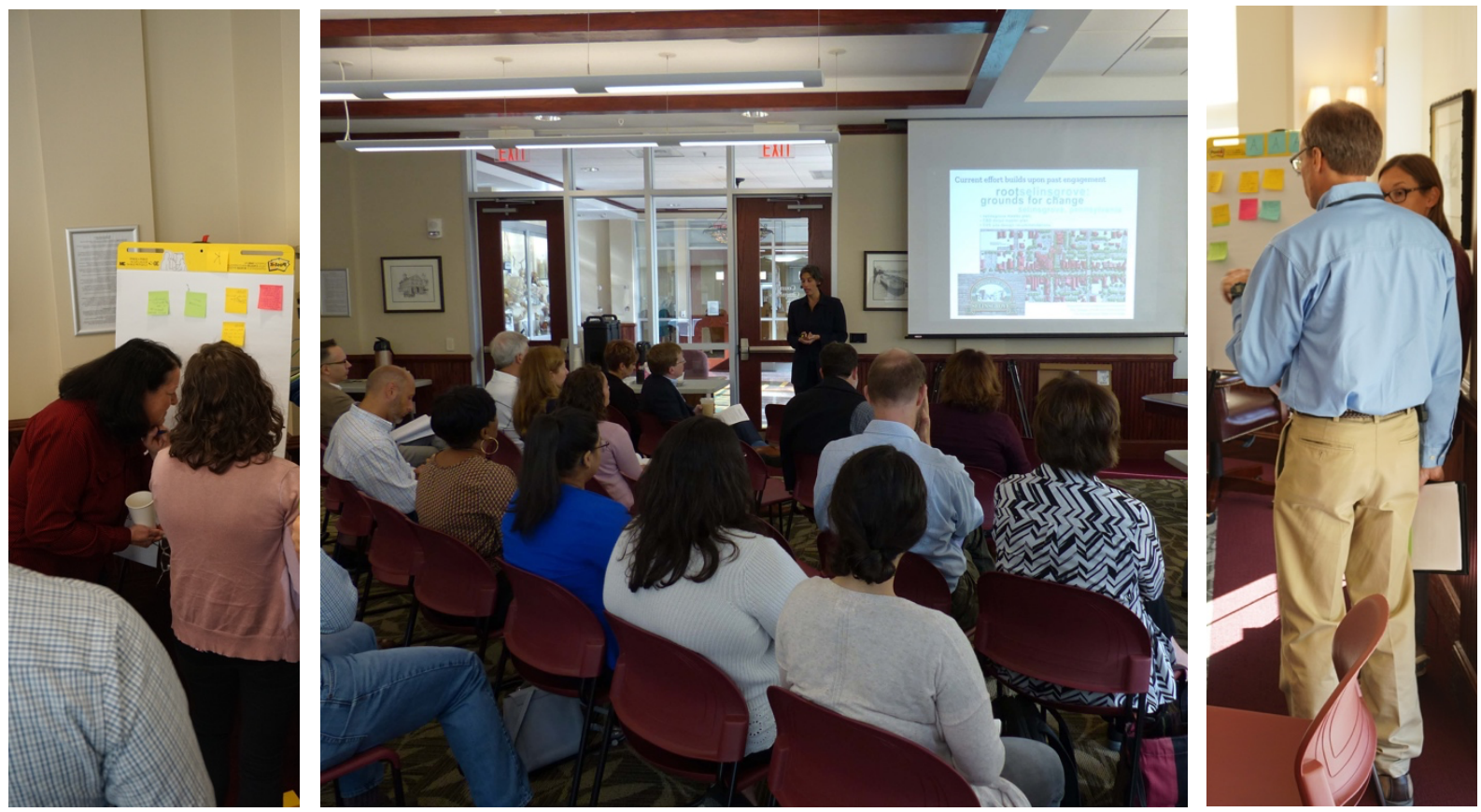

Prepared by:

The Penn State Initiative for Resilient Communities (PSIRC)

Communicating Author: Lisa lulo, Hamer Center for Community Design, Idi1@psu.edu

Additional Authors (in alphabetical order):

Aashna Arora, J.D. Candidate and Research Assistant, Penn State Law, aza5463@psu.edu

Lara Fowler, Penn State Law, Institutes for Energy and the Environment, Ibf10@psu.edu

Lacey Goldberg, Ph.D Candidate, Researcher, HCCD, Iks187@psu.edu

Casey Helgeson, Earth \& Environmental Systems Institute (EESI), helgeson@psu.edu

Klaus Keller, Center for Climate Risk Management (CLIMA), klaus@psu.edu

Robert Nicholas, EESI, ren10@psu.edu

Sanjib Sharma, Postdoctoral Scholar, EESI, svs6308@psu.edu

Nastaran Tebyanian, Ph.D Candidate, Researcher, HCCD, nzt117@psu.edu

Nancy Tuana, Rock Ethics Institute, Department of Philosophy, ntuana@psu.edu

Mahkameh (Maggie) Zarekarizi, Postdoctoral Scholar, EESI, mxz414@psu.edu

Abstract: This white paper provides an overview of priorities related to community resilience to flooding that emerged during a 27 September 2019 meeting with local, regional and state representatives in Selinsgrove, Pennsylvania. The document compiles workshop details, participants and a summary of discussions and outcomes. It does not, however, attempt to provide a comprehensive listing of every topic raised by participants. In addition, this workshop was held before the advent of covid-19; the impacts of this pandemic are not addressed in this document. 


\section{Background and Overview}

Penn State Initiative for Resilient Communities (PSIRC): Launched in January 2019, PSIRC provides an environment of shared discovery where people can come together to address local resilience challenges of small, riverine communities vulnerable to flood risk. Working with local stakeholders and decision makers, PSIRC provides a way to leverage the resources of Penn State to work with and help make an impact within local communities.

Selinsgrove Pilot Project: A pilot project is underway in the community of Selinsgrove, Pennsylvania; this community is representative of many communities along the Susquehanna River, along with others throughout the Commonwealth of Pennsylvania and the Chesapeake Bay Watershed. This pilot includes two components: 1) working with Selinsgrove Borough to develop a plan for community flood resilience and revitalization, and 2) broadly engaging with stakeholders and decision-makers about flood resilience in Pennsylvania's riverine communities in the Susquehanna River Basin.

Workshop Intent: The workshop intent was to gather information about priorities related to community vitality and flood resilience in Selinsgrove. This can then help inform priorities related to community resilience and identify other potential benefits to help meet community needs in Selinsgrove and beyond. The workshop purpose was not to make recommendations for particular actions.

\section{Workshop Participants:}

\section{Conveners:}

- H.W. "Skip" Wieder, Susquehanna River Heartland Coalition for Environmental Studies (SRHCES)

- PSIRC team members

\section{Participants:}

- William Bradfield, Flood Resiliency Analyst, SEDA-COG (now with Pennsylvania Emergency Management Agency, PEMA)

- Lindsey Brouse, Zoning and Floodplain Administration, Selinsgrove Borough

- Harry Campbell, PA Director, Chesapeake Bay Foundation

- John Coukart, Selinsgrove Borough Engineer, Coukart \& Associates, Inc.

- Malcolm Derk, Director of Grants \& Foundation Relations, Susquehanna University

- Wes Fahringer, Regional Advisor, NE Region, DCNR

- Adrienne Gemberling, Chesapeake Conservancy

- Sean Gimbel, PA Fish and Boat Commission

- Carol Handlan, Selinsgrove Projects, Inc.

- Joe Kleinbauer, former business owner and community volunteer, Selinsgrove, PA

- Marcus Kohl, Regional Director, PA DEP

- Sara Lauver, Selinsgrove Borough Council Member

- Yvonne Lemelle, DCED Regional Planner

- Dione Mercer, Researcher - Health and Blue Space, Geisinger Health System; Selinsgrove Borough Planning Commission

- Bobbie Owens, Borough Council Member

- Janet Powers, Selinsgrove Borough Flood Task Force, Borough Planning Commission

- Teri Provost, Director, Housing \& Flood Resiliency, SEDA-COG

- Marvin Rudnitsky, President, Selinsgrove Borough Council

- Katherine Straub, Professor \& Chair, Earth \& Environmental Sciences, Susquehanna University

- Jessica Trimble, Policy Specialist, DCED

- Helen Walters, Selinsgrove Area Chamber of Commerce

- Paul Williams, Selinsgrove Borough Manager (retired as of February 2020)

- Lori Yeich, Recreation \& Conservation Manager, DCNR 


\section{Summary}

\section{A. Workshop Description}

On September 27, 2019, participants from the Borough of Selinsgrove, regional and state agencies, and local universities gathered for a workshop convened by Skip Wieder and PSIRC in Selinsgrove, Pennsylvania. The workshop's purpose was to gather information from community advisors on priorities and values associated with community resilience to riverine flooding and to identify factors contributing to community vitality.

The workshop began with a presentation on PSIRC's approach and the workshop's projected goals and outcomes. Participants briefly introduced themselves, including the organization they represent, the scale/region at which they work, and key issues of importance to them or their organization.

Following the breakout discussions, everyone regrouped for an overall discussion. The information below is a summary of both the breakout sessions and the general discussion that followed; it does not represent every topic raised nor does it offer recommendations.

\section{B. Summary of Participant Feedback}

Challenges: Participants identified a number of challenges related to communication, "uncertainties," flood insurance and flood mitigation, environmental and infrastructure questions, availability and alignment of funding resources, and coordination. These are summarized below.

Many of the challenges associated with flooding were classified as "uncertainties" by workshop participants. These include lack of understanding and/or changing definitions of policy and regulatory environments. By and large, these challenges are associated with the Federal Emergency Management Agency (FEMA). In particular, misunderstanding of FEMA mapping, associated terms and practices, and the implications for development (where to build or not to build) were raised as challenges. These challenges were sometimes characterized as "lack of predictability" by participants. Even when and where FEMA maps are updated their accuracy now, and in the future, is uncertain. These challenges are related to the most predictable impacts of flooding associated with primary rivers (the Susquehanna and its major tributary, Penns Creek). Other smaller streams running throughout the Borough, Susquehanna University's campus, and through the region, are much less predictable as to when or how much they might flood. Flooding is also caused or exacerbated by increased rainfall and stormwater runoff. Finally, increases in development and stress on existing sewer and stormwater infrastructure is resulting in unpredictable flooding to properties located outside of anticipated areas that have flooded in the past.

Flood insurance itself is another challenge. Many properties in the Borough were constructed prior to the development of the initial Flood Insurance Rate Map in 1974 (pre-FIRM); current owners are now confronted with very high and increasing costs associated with flood insurance requirements. Exposure to flooding and/or high and increasing flood insurance premium costs have personal and societal impacts, including potential for deferring flood management/mitigation that results in damages and/or abandonment of properties, potentially eroding the tax base and leading to community blight. 
How to mitigate potential flood risk is another challenge. Property owners willing to mitigate flood risk are faced with questions about which mitigation strategies would lead to reduction in insurance premiums, whether or not to use federally available funds to execute a mitigation project, and what standard they should design to (for example, how high should a home be elevated above the base flood elevation (BFE) to ensure that they are safe from high water?).

Another set of challenges that emerged was related to broader environmental and infrastructure $\underline{\text { dynamics. }}$. These were addressed together or interchangeably since impacts on water quality from stormwater and flooding are leading challenges in Selinsgrove and other river communities. For example, transportation decisions impact walkability and affect local businesses and development increases impermeability and strains stormwater infrastructure while simultaneously constraining space for water quality and quantity control. Water quality, drinking water, urban stormwater management, and river health are local/regional challenges that need to be considered in relation to one another.

Questions related to funding and finances are a consistent challenge related to community vitality and flood resilience. Generally, limited or unknown financial resources and unclear benefits discourage people from complying with requirements and pursuing mitigation that could protect their property from flood impacts. In Selinsgrove specifically, Susquehanna University is a major economic driver, positively contributing to community infrastructure and businesses. However, as with other college towns, there are also challenges. Susquehanna University is a residential campus - the population lives and works mainly on campus. Therefore, it is perceived as having little presence downtown, creating conflicting challenges for local businesses. Currently, walkability and attracting/retaining businesses are challenges in the downtown area. Limited tax base in Selinsgrove raises concerns about acquiring properties for flood mitigation purposes. Approximately half of the properties in Selinsgrove Borough are tax exempt. In addition to Susquehanna University, a large K-12 campus of the school district and several churches hold land in the Borough.

Participants identified a strong need for and current lack of communication and coordination. For example, to address environmental and infrastructure issues, coordinating across municipal boundaries is an issue; infrastructure often crosses municipal boundaries and upstream decisions can impact downstream communities and waterways. Limited communication and coordination are challenges to larger-scale planning initiatives, and the ability to capitalize on available funding, contributes to a perception of less available funding from state and federal sources than may actually be the case. There are also challenges associated with aligning available funds with community needs. Moreover, it is difficult to combine multiple funding sources in sensible ways. Local communities (there are over 2500 individual municipalities in the Commonwealth of Pennsylvania) may not have the expertise, experience, or bandwidth to identify and take advantage of funding opportunities.

Finally, some participants noted that the prevalence of a "sunny day" mentality leads people to forget about past flooding and its impacts on individuals and the community. This can pose a challenge to enacting proactive intervention, leading to political inertia and exacerbating local resistance to change. 
Actions: Participants identified a number of action items that could be taken. Planning, investment (funding), and coordination/education/engagement are interrelated themes when considering actions to be taken now and in the future.

There is a need for planning across scales (physical and temporal scales) and jurisdictions. Such planning often must address complex trade-offs. Moreover, development interests may be in conflict with actions to mitigate flooding. While maintaining floodways and land immediately adjacent to waterways as open space is a preferred flood risk reduction measure, such a measure has implications for already built public and private properties. Development presents immediate risk to buildings constructed in regulatory floodplains (properties and critical facilities included in the 100-year and 500-year regulatory floodplains) and potentially creates obstructions and increased flooding for others. Moreover, allowing development to occur in regulatory floodplains could compromise a municipality's Community Rating System (CRS), resulting in increased insurance rates for everyone with federal flood insurance. [Note: this is a complex area with a number of legally defined terms. This description is not meant to provide legal guidance but to give a sense of issues raised during the workshop].

For action to occur at local and regional scale, participants noted that engagement with and across several political entities is needed. Some actions, such as river and adjacent open space conservation, need to be addressed based on watershed rather than political boundaries. Moreover, participants suggested that action should be informed by how nature functions, with greater investment in green infrastructure and less in grey infrastructure (i.e. storm sewers, pipes, culverts).

Participants also highlighted funding and investment as a key area for potential action. In Selinsgrove and similar communities, there is a need for investing in downtown areas, rather than on the outskirts. Related to infrastructure, interest in investing more in green infrastructure and less in "gray" infrastructure, was expressed. Action should also be taken to prioritize infrastructure investment under climate change scenarios, addressing impacts of climate change projected to affect Pennsylvania. Proactive action to initiate projects is needed. For these projects to be competitive, collaboration and alignment with state agencies and plans (i.e., Restore PA (potential), CDBG, PENNVEST, DCNR, Fish and Wildlife) leverage federal and state funds. Acknowledging municipal power within the Commonwealth of Pennsylvania is also important.

To avoid conflicts between actions and to capitalize on available funding, participants noted the importance of coordinating local and regional planning and to consider flood risk and uncertainties. Action related to education and engagement are important to understand potential results of planning decisions and to inform the public and decision makers.

Knowledge: Workshop participants identified a wide range of knowledge gaps.

Participants recognized a need for scientific data, such as enhancing understanding of the temporal dynamics of floodplains, enhancing accuracy of watershed data, and contributing to knowledge of future flood hazards projections to communicate uncertainties that can lead to better outcomes and actions. 
They also noted that there is a need to better understand existing regulations. For example, there is a need for education for both the public and municipal staff on FEMA's National Flood Insurance Program (NFIP), options and costs, and watershed regulations.

Knowledge of mitigation strategies and best management practices (BMPs) - i.e. when, where, what, potential tradeoffs - is important. Participants observed that accounting for knowledge must be carefully considered in the context of place and time: a BMP for one location may not be ideal for another and today's BMP may not work under future conditions. Knowledge of BMPs that contribute to multiple objectives, such as flood control and water quality, is important. However, these objectives may be in conflict with other community desires. For example, strategies such as planting trees may provide multiple benefits; however, conflicts may arise between installations that improve water quality (i.e. riparian buffers) and those that allow for recreational opportunities.

There is also a need for knowledge related to adaptive strategies that account for future changes and current decision-making (for example, decisions related to structural elevation of houses) as well as the costs associated with BMPs. These costs may include initial costs for design and implementation, but also longer-term costs of maintenance. In Selinsgrove, knowledge is needed to inform about flood potential and impacts of local streams and tributaries (Weiser Run) and implications of upstream agriculture and land use, pre- and post-development conditions, and on waterway performance and maintenance.

Values: The values and preferences voiced by participants most frequently during the workshop discussion focused on two key areas: 1) quality of life, and 2) economic resilience.

Quality of life was often expressed in terms of the health and well-being of the residents and the health of the local environment. This included aquatic health, water quality, and preservation of recreational opportunities, particularly river recreation. Aesthetic factors such as protection of historical places and maintaining the charm of the community were also often included under the category of well-being. Aesthetic value was equally connected to the river towns' historic charm and to the environmental beauty of the area. The Susquehanna River, embedded in the history of Selinsgrove, was seen as key to quality of life for both recreation and natural beauty.

Economic resilience was expressed in the context of both individual and community needs, with a key focus being flood resilience. The emphasis on individual economic resilience concerned protection of property from flooding and job opportunities. Community-wide economic resilience focused primarily on the economic vitality of the downtown area as a key element of community vitality. Strengthening the relationship between the downtown and Susquehanna University was also identified as a key component of economic resilience. In general, a thriving downtown, a strong tax base, and protection of property values were identified as economic issues of importance and value in this community.

Participants often saw these two general areas of value as interdependent. The economic resilience of the downtown area was viewed as directly linked to community well-being. The values related to the health and beauty of the river and surrounding environment were, in turn, seen as linked to economic resilience as they attract residents as well as visitors. Flood resilience was identified as a key factor in both domains. 


\section{Conclusions and Next Steps}

Brief conclusion: The workshop provided a good initial forum for both Selinsgrove and broader participants to focus on flooding and community vitality: what are the challenges, potential actions, knowledge gaps, and values at play? The thoughts shared by workshop participants highlight the continued need for coordination and communication to address flooding in Selinsgrove and other flood-prone riverine communities.

The information shared in this summary represents a compilation of what we heard; it does not represent any advice or recommendations. We welcome the questions or comments from workshop participants, then will circulate a final draft more broadly.

Next steps: In addition to this workshop, members of the PSIRC team reached out to a broader set of potentially interested stakeholders at the 2019 Pennsylvania Association of State Floodplain Managers (PAFPM) annual conference in Harrisburg, the 2019 Susquehanna River Symposium at Bucknell University in Lewisburg, Pennsylvania, and the National Council for Sciences and the Environment (NCSE), in Washington, D.C. The findings of this workshop combined with this broader outreach are resulting in the following pilot project action items:

1. Discussion on how to compile and share relevant data and information to answer questions raised during the workshop;

2. Development of a set of questions for individual interviews;

3. Planning for a broader community event (fall of 2020)

Going forward, focused research and enhanced communication of knowledge between groups (i.e. scientists, planners, community decision-makers and members) is needed. Moving from knowledge to action has the potential to reveal trade-offs, must account for uncertainty, and needs to bridge regulatory and political constraints. How to handle likely trade-offs between values can be a source of conflict but also an opportunity for dialogue, identification of additional knowledge, data and needs, and sound decision making. Feedback on challenges, values, knowledge and actions will be used to inform and improve decision making processes.

Acknowledgements: This work is supported through the Penn State Initiative for Resilient Communities (PSIRC) by a Strategic Plan seed grant from the Penn State Office of the Provost and is being undertaken in partnership with the Center for Climate Risk Management (CLIMA), the Rock Ethics Institute, Penn State Law, and the Hamer Center for Community Design. Special recognition to H.W. "Skip" Wieder for convening the workshop in Selinsgrove, PA and soliciting PSIRC's ongoing participation. A version of this report was previously published in the conference proceedings of the EAAE-ARCC International Conference $\& 2^{\text {nd }}$ Valencia International Biennial as "University-community partnership to address flood resilience and community vitality;" It is available through the RIUNET repository, the catalogue of the Editorial Universitat Politècnica de València, the conference website (https://www.eaae-arcc-ic.upv.es/), and in printed version. 